\title{
Determinants of knowledge sharing using Web 2.0 technologies
}

\author{
Sotirios Paroutis and Alya Al Saleh
}

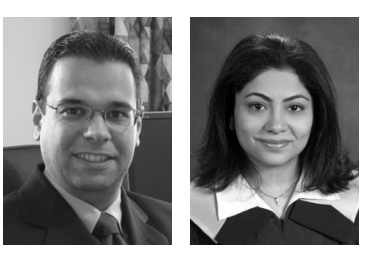

Sotirios Paroutis is an Assistant Professor of Strategic Management at the Warwick Business School, University of Warwick, Coventry, UK. Alya Al Saleh is currently a Business Analyst at Shell E\&P International.

\begin{abstract}
Purpose - The purpose of this paper is to investigate the key determinants of knowledge sharing and collaboration using Web 2.0 technologies by exploring the reasons for and barriers to employees' active participation in its various platforms within a large multinational firm.
\end{abstract}

Design/methodology/approach - This study is based on a case study design. In total, 11 in-depth interviews were conducted. In addition, secondary data was collected. The data was analysed using a grounded approach.

Findings - The authors reveal four key determinants of knowledge sharing using Web 2.0 technologies: history, outcome expectations, perceived organizational or management support and trust.

Research limitations/implications - The limitations are related to the small sample size and the assumptions on which the study was based. First, Web 2.0 technologies were perceived as a single set of technologies whose adoption and use is determined by the same range of factors. Secondly, the study assumes that knowledge sharing using Web 2.0 is an effective means to collaborate.

Practical implications - Managerial recommendations derived from this study include: playing an active role in supporting Web 2.0 technologies as a strategic knowledge management initiative, clearly communicating its benefits, providing the necessary training and finally, rewarding participation.

Originality/value - Online collaboration tools have become the knowledge management tool of choice for an increasing number of organisations. However, very little is known about factors leading to their success or failure. This study narrows this gap by offering unique empirical evidence from TechCo (pseudonym), one of the largest companies deploying such technologies.

Keywords Communication technologies, Employee participation, Knowledge sharing

Paper type Research paper

K nowledge is increasingly being seen as the most important strategic asset in organizations and a crucial resource to achieve sustainable competitive advantage (Davenport and Prusak, 1998; Drucker, 1999; Ipe, 2003). Given that a significant amount of organizational knowledge resides in the minds of employees, it is important for organizations to understand what motivates employees to share knowledge and what prevents them from doing so. When organizations understand the determinants of knowledge sharing and exchange among employees, appropriate management practices can be implemented to encourage such behaviour and thereby enhance productivity, innovation and overall organizational competitiveness.

The recent knowledge management literature has emphasized the importance of interactive knowledge management technologies (manifested widely in virtual communities) in brining the human side into the knowledge management equation (Ardichvili et al., 2003). The most recent of these technologies are blogs, wikis and other social media collectively dubbed as Web 2.0 technologies or Web 2.0 platforms (Levy, 2009; Weinberger, 2007). It is argued that such technologies have distinct technical features that unleash passion for engaging in knowledge sharing and addresses drawbacks in the current technologies used within organizations. Thereby, conventional barriers to sharing knowledge could be overcome 
(Kaiser et al., 2007; McAfee, 2006a). Given these benefits, an increasing number of organizations are beginning to introduce Web 2.0 technologies internally (Bughin and Manyika, 2007; Dennison, 2006). TechCo[1], whose case will be the focus of this paper, is one of the largest companies currently deploying these tools. However, given the novelty of Web 2.0, very little is known about the benefits it yields to the end-user and the factors leading to its successful implementation within organizations. Therefore, the objective of this study is to contribute to the understanding of factors determining the success of knowledge sharing using Web 2.0 technologies by exploring the reasons for and barriers to employees' active participation in these platforms. This, in turn, enables us to develop recommendations that can help organizations to leverage the most out of their Web 2.0 technologies and maintain platforms in which employees have both the opportunity and the motivation to participate.

\section{The evolution of knowledge management and Web 2.0}

According to Kuhlen (2003), the understanding of knowledge management has undergone a paradigm shift from a static, knowledge-warehouse approach towards a more dynamic communication-based or network approach. Similarly, Hazlett et al. (2005) maintain that the literature in knowledge management has moved away from focusing on the explicit dimensions of knowledge (i.e. the computational paradigm) to the tacit dimension of knowledge (i.e. the organic paradigm). The latter paradigm, unlike the former one, Hazlett et al. (2005) argue, is a dynamic, people-centric approach that takes into account cultural problems and motivational issues in knowledge sharing.

The term "Web 2.0" was officially coined by O'Reilly Media in 2004 (O'Reilly, 2005). It refers to a perceived second generation of community-driven web services such as social networking sites, blogs, wikis, etc. which facilitate a more socially connected web where everyone is able to communicate, participate, collaborate and add to and edit the information space (Anderson, 2007; Ankolekar et al., 2008; Pachler and Daly, 2009; Rollett et al., 2007). Given the aforementioned characteristics, Web 2.0 has also been commonly referred to as the "social web". Participation is a key feature of Web 2.0 which is structured around open programming interface that allows any user to freely create, assemble, organize (tag), locate and share content (Boulos and Wheeler, 2007). Web 2.0's participatory nature is best exemplified in Wikipedia where people work collaboratively to input, produce and update knowledge as opposed to the traditional encyclopaedias where the information is static and predetermined. The interactivity of blogs compared to personal web sites is another example of Web 2.0's participatory nature which stands in sharp contrast to the access-control in applications commonly used in organizations. In the following section, the application of Web 2.0 in the enterprise will be discussed.

\section{Enterprise 2.0: key characteristics and benefits}

Organizations have realized that Web 2.0 technologies could be leveraged for business advantage and have thus become interested in replicating the outcomes of Web 2.0 inside their own enterprises. This gave birth to the concept of Enterprise 2.0 which is basically the application of Web 2.0 technology within the organizations (Kainy, 2007; Semple, 2007). McAfee (2006b) found that when companies make Web 2.0 technologies widely available, the only two groups that quickly start using them are "techies" and "newbies". He defines "newbies" as the new entrants to the workforce such as recent graduates who find it natural to socialize, collaborate, and find what they are looking for through the various technological platforms available. "Techies", on the other hand, are defined as IT staff and other technically-astute employees across the company who are the natural early adopters and advanced users of new technologies (McAfee, 2006b).

The literature on Web 2.0 has thus far focused on the organizational benefits of Web 2.0 technologies. However, the important question to ask here is what are the real benefits to the actual users, the employees? And what are the other factors that motivate employees to use these tools? This is the specific area where this study aims to contribute. Existing literature on knowledge management has already identified many of the motivations and barriers to knowledge sharing. An overview of these determinants is presented next.

VOL. 13 NO. 42009 JOURNAL OF KNOWLEDGE MANAGEMENT $\mid$ PAGE 53 


\section{"Web 2.0's participatory nature is best exemplified in Wikipedia where people work collaboratively to input, produce and update knowledge as opposed to the traditional encyclopedias where the information is static and predetermined."}

\section{Determinants of knowledge sharing}

The knowledge management literature has identified a wide range of factors that influence knowledge sharing behaviour. These factors could be summarized into the following three categories: technological factors, organizational or environmental factors, and individual or personal factors (Ardichvili et al., 2006; Cabrera et al., 2006; Barson et al., 2000; McDermott and O'Dell, 2001; Riege, 2007). Although the present study examines Web 2.0 technologies, the focus will not be on technological factors because technology, as McDermott (1999) argues, can inspire knowledge management but cannot deliver it. Accordingly, the research questions of this study are designed to focus on the human and organizational factors or the social aspects of knowledge sharing. These questions are adapted from Ardichvili et al.'s (2003) study on motivations and barriers to participation in virtual communities of practice. Overall, this study addresses the following questions:

- What are the reasons for employees' willingness to use and/or contribute their knowledge to Web 2.0 platforms?

- What are the barriers to employees' willingness to use and/or contribute their knowledge to Web 2.0 platforms?

\section{Method}

\section{Data collection and analysis}

This research is based on a qualitative case study design with the main unit of analysis being individual employees. Qualitative research was chosen as the most appropriate strategy given the limited availability of literature on knowledge sharing using Web 2.0 technologies. Further, this study is based on the premise that knowledge can be created, shared and used by employees across all organizational levels and functional areas. Therefore, unlike many studies on knowledge management which focus on knowledge workers[2] (Bock et al., 2005; Chennamaneni, 2006), in this research any employee regardless of their organizational role and position is a subject of interest. For the face-to-face interviews, a combination of convenient and snowball sampling was used. In order to get more representative responses, a random sample of TechCo bloggers were also contacted through the firm's external blog directory. Three of them responded agreeing to participate in the interviews. By the end of the study a total of 11 employees were interviewed (five users and six non-users of Web 2.0). The interviews were recorded and lasted on average 30 minutes. In order to provide a more thorough analysis, secondary data about the knowledge management programs and Web 2.0 technologies in TechCo were obtained from official sources. An example of this secondary data are the internal Q\&As about the reasons for blogging that are conducted internally across TechCo. Responses to these Q\&As were integrated into the findings of this study.

A grounded theory approach was used in the analysis of the data (Strauss and Corbin, 1990). The analysis started with coding the answers in categories that are indicative of motivations and/or barriers to knowledge sharing using Web 2.0 technologies. In order to enhance the validity of the findings, each of the categories had to be supported by multiple respondents who also had to provide instances of how a particular factor has influenced 
their knowledge sharing behaviour. Before describing the findings, an overview of TechCo and its knowledge management strategy is provided next to contextualize the issues and themes to be discussed in the remainder of the paper.

\section{Contextual setting: TechCo and its knowledge management strategy}

TechCo is a multinational technology and services corporation. During the 1990s, it underwent a difficult period as markets shifted and it needed to reinvent itself to compete across a new landscape. As a result, various knowledge management programs were initiated to foster knowledge exchange within and across its business units. The different knowledge management initiatives focused on different areas from intellectual asset management to collaboration. TechCo's asset management tools include discussion forums and other community facilities which are designed to capture and make available intellectual assets for future reuse. In the area of collaboration, TechCo provided employees with virtual spaces that encourage remote teams to virtually share information and collaboratively work together. All the aforementioned programs focus primarily on explicit knowledge exchange through intellectual knowledge repositories as opposed to a more balanced approach between explicit and tacit knowledge. They employ tools which are, to a large extent, static; have limited, departmental access; and offer a very structured methodology for knowledge sharing and collaboration. It is only recently that TechCo started introducing social software tools and Web 2.0 technologies which focus on tacit knowledge exchange through an emergent rather than a structured approach to participation and collaboration. In the following sections, the findings regarding knowledge sharing using Web 2.0 technologies in TechCo will be presented.

\section{Findings}

The study results are presented below, grouped according to participation versus non-participation in Web 2.0 and according to the key research questions. The sample responses provided in the tables include comments made by both participants interviewed during this study and respondents to the Blogging Q\&A conducted internally by TechCo[3]. It is after analysing the following responses that the common themes and key determinants presented in the discussion section were derived.

\section{Users of Web 2.0: Reasons and/or motivations for employees' willingness to use/contribute} their knowledge to Web 2.0 platforms

When asked about their reasons and motivations for participating in Web 2.0, employees mentioned a wide-range of benefits and outcomes that acted as motivators for their participation. These benefits included: effective communication (in terms of ease of use, speed and reach) (see responses below - 1.1, 1.3), managing personal knowledge (1.2), generating discussion about new concepts and ideas, finding answers to particular problems, staying informed about the latest news and activities of fellow colleagues (1.3) and receiving desired help and feedback. Other mentioned outcomes resulting from using Web 2.0 and which also acted as motivating factors included aspects such as increasing one's social network (both personally and professionally) (1.4) and building a level of credibility tied to the individual employee. Satisfaction in helping others and passion about certain topics and one's area of practice were some other mentioned reasons.

Sample responses from Web 2.0 users illustrating reasons and motivations for employees' willingness to use/contribute their knowledge to Web 2.0 platforms:

- 1.1. "It was also about sharing information - at TechCo I frequently get called up to ask if I've seen $\mathrm{x}$ or y problem before, so I can now just point people at my blog".

- 1.2. "I originally started blogging to note down useful things l'd learned in my job that evolved into writing about what l'd been doing, so the blog became a journal and a record".

- 1.3. "Since I work on-site with our customers I don't always see other colleagues as often as I might like, so keeping a blog enables the rest of my team to keep up with my activities (and I can follow the blogs of my team mates)". 
- 1.4. "In the ever-changing world, it's helpful to build a level of credibility tied to you as an individual. l've built professional connections world-wide that would not otherwise exist, as a result of my blog".

Users of Web 2.0: barriers to employees' willingness to use/contribute their knowledge to Web 2.0 platforms

Current users expressed a number of factors that could act as potential barriers to their participation in Web 2.0. One of the most commonly stated barriers was if no one else used or contributed to them (see responses below - 2.1). Lack of support and recognition from the organization was also stated as a factor that could adversely affect their participation (2.2). Most users expressed the importance of having their ideas and efforts acknowledged one way or another. Another reason was information overload (2.3, 2.4). Employees' concerns did not revolve around finding enough information as much as around navigating through the information overload in order to obtain what they are looking for. Trust or its lack thereof was another potential barrier. Different dimensions of trust were mentioned including: trusting the quality and accuracy of the information $(2.3,2.4)$, trusting that others will treat the information they share with care (2.2) and trusting that others will reciprocate and provide the necessary help when needed. Fear of publishing something confidential or violating company policy was also mentioned as a factor that could hinder participation in various Web 2.0 platforms.

Sample responses from Web 2.0 users illustrating (potential) barriers to employees' willingness to use/contribute their knowledge to Web 2.0 platforms:

- 2.1. "The risk is that you spend time contributing to them and that people do not use the information you publish".

- 2.2. "When people take credit for your ideas. There is enough of that going around!".

- 2.3. "I think there is information overload and much of it is useless. Blogs have a connotation of people talking about silly and trivial things in their private lives".

- 2.4. "There is too much information you have to filter it".

Non-users of Web 2.0: barriers to employees' willingness to use/contribute their knowledge to Web 2.0 platforms

Time was one of the most commonly stated barriers (see responses below - 3.1). Lack of knowledge about the tools, their benefits and how to go about using them, unawareness or cynicism about the value they could provide, and perceptions of certain risks and downsides associated with using Web 2.0 (3.2) were among the top mentioned barriers. The effectiveness and convenience of using existing tools also adversely affected the willingness to adopt Web 2.0 (3.3). Furthermore, perceptions of lack of organizational or management support in terms of communicating the benefits, providing the necessary training and rewarding and recognizing efforts and contributions were commonly mentioned. Fear of violating company policy was raised by respondents who felt that blogging guidelines and new caveats attached to employee communication acted as inhibitors to express one's ideas more openly in the different Web 2.0 platforms.

Sample responses from non-users of Web 2.0 illustrating barriers to employees' willingness to use/contribute their knowledge to Web 2.0 platforms:

- 3.1. "Time is the main factor. And it's knowing what is out there and knowing what discussions are going on. Have I got anything to input into them?".

\section{"The important question to ask here is what are the real} benefits to the actual users - the employees?" 
- 3.2. "There is too much information at times where you can actually be misled because it could come from a non-reliable source. The amount of information and the detail is far greater but the accuracy has dimensioned over time. Ten years ago we were succinct and we captured the minimum amount of information but it was right and it was verified and you knew what was there and you could totally rely on it".

- 3.3. "I think it is history because there are ways of communicating that we are used to. It is easier and more comfortable to do it the old way. You've got a traditional way of accessing and gaining information and you know how to do it quickly. It's almost second nature... you automatically default into what you're used to".

\section{Non-Users of Web 2.0: reasons and/or motivations for employees' willingness to use/contribute their knowledge to Web 2.0 platforms}

Most of the reasons and motivations that non-users expressed were related to the absence of barriers preventing them to participate in the first place. For example, when they were asked about what could motivate them to use Web 2.0 technologies, the most common response was that if they derived certain benefits from using them (see responses below 4.1, 4.2, 4.3). Another motivation was having their contributions be recognized. With the exception of one employee, financial rewards or hard incentives were not mentioned as motivating factors (4.3). Employees also stated that general support and endorsement of Web 2.0 by top management would positively influence their decision to participate.

Sample responses from non-users of Web 2.0 illustrating reasons and/or motivations for employees' willingness to use/contribute their knowledge to Web 2.0 platforms.

- 4.1. "If I found something useful on a blog or a wiki and it helped me then that will motivate me to give back. I will feel obliged to give back".

- 4.2. "It's the speed of execution and the ability to generate more business that would motivate me to use blogs, wikis or any other tool".

- 4.3. "If it helped me generate more money. I'm a salesperson and money motivates me".

\section{Discussion: determinants of knowledge sharing and collaboration}

The purpose of this research was to identify the key determinants of knowledge sharing and collaboration using Web 2.0 technologies. After a thorough content analysis and close examination and comparison of the responses, the following categories were derived: history, outcome expectations, perceived organizational/ management support and trust. Following is an in-depth discussion of each determinant and how it relates to the social psychology, organizational behaviour and knowledge management literatures.

\section{History}

History or "the old/established way of doing things" appeared to be one of the main barriers to knowledge sharing and collaboration using Web 2.0 technologies. Although some non-users acknowledge the potential benefits of Web 2.0 and the limitations of currently used tools (e.g. the two-way nature of instant messaging); they have stated that the familiarity of these tools and their widespread use across the organization makes the adoption of Web 2.0 not very compelling:

I think it is history because there are ways of communicating that we are used to. It is easier and more comfortable to do it the old way. You've got a traditional way of accessing and gaining information and you know how to do it quickly. It's almost second nature... you automatically default into what you're used to.

While some employees suggested that knowledge sharing using current tools is one reason behind their non-participation in Web 2.0; others indicated that the company's focus on promoting these tools rather than Web 2.0 technologies is another key reason. This finding is consistent with Richard Thaler's (1980) endowment effect theory which posits that people place a higher value on objects they own (their "endowment") relative to objects they do not and they mentally compare having the prospective item to giving up what they already have.

VOL. 13 NO. 42009 JOURNAL OF KNOWLEDGE MANAGEMENT $\mid$ PAGE 57 
As a result, current tools such as e-mail appear to be more valuable than new tools like blogs and wikis. In the context of Web 2.0, McAfee (2006c) posits that the average person will underestimate the prospective benefits of blogs and wikis and overweigh everything they are being asked to give up by not using e-mail, instant messaging and other existing technologies. Of course, Web 2.0 is not designed to replace existing tools but the perception that new technologies can disrupt the status quo acts as an inhibiting factor.

It is not only employees' existing or previous behaviour that adversely affects adoption of new tools but companies' past and existing strategies and approach to knowledge management plays a significant role as well. Several respondents have stated that TechCo's focus on promoting static tools makes the idea of adopting Web 2.0 technologies less attractive. Thus, given the inertia imposed by "history", managers will have to consider issues like inducing change on different levels when introducing Web 2.0 technologies. This would entail, for example, redefining and communicating a new knowledge management strategy. Managers will also have to address issues like the endowment effect. According to McAfee (2006c) there are two broad strategies to address this problem of endowment; either increasing the perceived benefits of these tools or lowering their perceived costs and drawbacks. This leads us to the next key determinant of knowledge sharing using Web 2.0 and that is outcome expectations.

\section{Outcome expectations: perceived benefits and rewards}

Employees who perceived and gained positive outcomes from using Web 2.0 technologies were the one's actively participating; while those who were unaware of the benefits, sceptical about them and/or perceived the costs of using these tools to be higher than the benefits were the ones refraining from using them and who constitute what McAfee (2006b) dubs as the "Empty quarter". This points out to the fact that outcome expectations are a key determinant of knowledge sharing using Web 2.0 technologies.

Outcome expectations refer to the expected consequences of one's own behaviour (Hsu et al., 2007). The importance of outcome expectations in determining knowledge sharing is consistent with the value-expectancy theory which states that "an individual's behaviour is a function of the perceived likelihood, or expectancy, that his or her behaviour will result in a valued outcome" (Cabrera and Cabrera, 2002). The majority of current users stated that they use Web 2.0 partly because it helps them do their jobs more effectively. Some of the most commonly stated benefits include reducing e-mail overload, avoiding answering the same questions multiple times, managing personal knowledge, generating discussions on areas of interest, obtaining help in solving business problems and communicating more effectively with remote team members. One user also mentioned how conversations over Web 2.0 platforms are a good alternative to the "water cooler conversations" that can no longer take place due to increasingly working from home and on customer sites.

Some sample comments from respondents that exemplifies these benefits were:

- "To get feedback on what my division does".

- "[To] generate discussion about new concepts, ideas, opportunities, news, and competition".

- "To communicate more effectively with the people I work with".

- "[To] avoid answering the same question multiple times".

In terms of socio-personal outcomes determining participation and engagement in Web 2.0, recognition was a key factor. Current users expressed the importance of having their contributions recognized by their superiors and receiving credit for any ideas they share in the organization (see quote below). For them, recognition is another way to establish their credibility and expert status. This is consisted with previous studies which indicate that employee recognition from senior management directly motivates people to share knowledge (Oliver and Kandadi, 2006). 
- "The kudos you get from contributing to such tools and the network of contacts you build up as a result of using them."

- "It is very nice to do favours for people. If you help them, then they'll help you."

- "To the individual the benefit is the fact that you know you have done your bit and are helping others."

A significant amount of respondents also participated in Web 2.0 because they enjoyed helping others. This intrinsic enjoyment in helping others through sharing knowledge has been documented in many previous studies (Davenport and Prusak, 1998; Wasko and Faraj, 2000). For these Web 2.0 users, the value that others obtain from their contributions is equally important to the value they gain individually:

One thing that would discourage me from using them would be if no-one else was gaining value from them (i.e. if my blog received no hits or comments) and with respect to wikis if I felt I was the only one contributing

What is clear from this study is that the nature of rewards and incentives derived from Web 2.0 are very psychosocial in nature and do not involve tangible or hard rewards such as monetary compensation. This is consistent with the social exchange theory (Blau, 1964) which posits that "individuals engage in social interaction [e.g. knowledge sharing] based on an expectation that it will lead in some way to social rewards" (Akkinen, 2005). These social rewards include things like approval, status, respect, praise, recognition, positive feedback and mutual benefits. Results from prior research on virtual communities of practice are also consistent with the social exchange theory and provide evidence that all the aforementioned factors are strong motivators for active participation (Ardichvili et al., 2003; Hsu et al., 2007; Wasko and Faraj, 2000, 2005).

\section{Perceived organizational/management support}

After carefully analyzing the data, many different aspects of organizational or management support- from promoting and communicating the benefits to providing the necessary training and rewarding participation- appeared to be key factors determining knowledge sharing and collaboration using Web 2.0 technologies. Sample responses illustrating the different elements of this finding are:

- 'We haven't been given the education. . . the company hasn't taken the time out to say look guys these are new ways of communicating and there are real advantages".

- 'Responsiveness on sharing like a 'thank you' or 'great this is a good opportunity for us to do this or that' is very important and will encourage me to share. It will make it worthwhile to share knowledge. I don't think getting paid to share information will be effective. I think that's not the way of doing it."

- "If it is introduced properly to employees, I think I will use them. I think things fail because they are not introduced properly".

These responses demonstrate that many elements of managerial support that emerged in this study are related to basic implementation issues such as creating awareness about the tools, promoting their usage and communicating the benefits to encourage adoption among employees. These findings are consistent with previous studies (e.g. Cabrera et al., 2006) which indicate that that top management can send strong messages to the organization as to how important sharing knowledge is and people will be more inclined to perform a certain behaviour if they feel that important referent individuals endorse this behaviour and are likely to approve and even applaud it.

Training was found to be another important element of organizational/management support that influenced participation in Web 2.0. Many employees indicated that they do not use Web 2.0 either because they do not know how to go about using the tools or they have attempted and gave up due to the difficulties they have encountered. Currently, TechCo does not offer any formal training on using Web 2.0 technologies. Its approach is more 


\section{"The results of this study highlight 'trust' to be a key determinant of participation in Web 2.0 platforms."}

towards "go there and experiment". There are some conference call events to help introduce the topics, but nothing like an organised course or any formal sessions. Although TechCo is a technology-oriented company, only about a third of TechCo's population is "tech savvy". Therefore, training is important both in terms of providing the necessary education to enable employees to get the most out of the tools but also in terms of communicating a commitment to Web 2.0 and an investment in the employee both of which will positively affect Web 2.0 participation. The importance of training for the adoption and continued use of new technology have been identified by many researchers namely Rogers (1994) in his study on computer supported cooperative work.

This importance of organizational/management support is an interesting finding because the spontaneous success of the different Web 2.0 applications in the internet - from Wikipedia to the Blogosphere - have led many to believe that top management has a very limited role to play in the introduction and encouragement of Web 2.0 technologies in the enterprise. The advantages of these tools and the inherent network effects are believed to eventually lead to the diffusion and routinization of these tools. As a result, many companies have adopted the attitude "if we build it, they will come" (McAfee, 2006a). However, the findings clearly point out to the fact that the use of Enterprise 2.0 technologies depends on decisions and actions taken by managers (McAfee, 2006a). Overall, the present study indicates that even early adopters need support and encouragement.

\section{Trust}

The results of this study highlight "trust" to be a key determinant of participation in Web 2.0 platforms. Given the open and informal nature of Web 2.0, employees posed questions on whether they can trust the quality/accuracy of the information being shared and whether bloggers and wiki contributors "knew what they were talking about". In fact, previous research studies (e.g. Abrams et al., 2003) have suggested two dimensions of interpersonal trust that promote knowledge sharing in the aforementioned context: benevolence and competence. Benevolence-based trust is grounded in the emotional bonds between individuals and refers to faith in the trustworthy intentions of others. Competence-based trust, on the other hand, places emphasis on the cognitive component and refers to confidence in the ability and expertise of others. Respondents' concerns over the quality, reliability and relevance of the information can be regarded as issues associated with competence-based trust; while concerns over whether others will misuse the information, take credit for it, or not reciprocate their efforts can be associated with benevolence-based trust. With regards to reciprocity and trust, this study has shown that participants in Web 2.0 who blog about certain issues or pose certain questions would like to receive comments or some sort of feedback, the lack of which would diminish trust in their colleagues.

An interesting finding from this research is that trust is not only a prerequisite for knowledge sharing and collaboration using Web 2.0 technologies but also, to a large extent, the outcome of such sharing and collaboration. So, while it is impossible to build a virtual environment of knowledge sharing and collaboration without general trust; once such activities take place, they enhance and reinforce trust until it becomes self-perpetuating. Many of the respondents have been able to establish and maintain strong social networks virtually that did not exist before Web 2.0 technologies were introduced.

\section{Conclusion}

This study identifies the key determinants of knowledge sharing and collaboration using Web 2.0 technologies by exploring the reasons for and barriers to employees' active 
participation in its various platforms within a large multinational firm. Using insights from both users and non-users of Web 2.0, the following four key determinants were identified: history, outcome expectations, perceived organizational/management support and trust.

More importantly, a number of managerial implications can be derived from these findings. First of all, it is highly recommended that top management take an active leadership role in introducing Web 2.0 technologies, communicating their benefits and articulating how they fit into the organization's knowledge management strategy and, ultimately, how they could help achieve organizational objectives. It is equally important to provide the necessary training and have the appropriate reward systems in place. It is also important for management to avoid mandating or enforcing knowledge sharing using Web 2.0. Further, as this study has shown, rewards in the form of recognition are critical for encouraging knowledge sharing in Web 2.0 platforms. Therefore, companies involved in implementing Web 2.0 should consider introducing soft rewards like praise and recognition to encourage employee participation. For instance, having a recognition programme where the "most active blog", "top rated blog post" or "best wiki contribution" is publicized on the company's intranet or internal newsletters is one effective way to recognize employees' contributions.

\section{Notes}

1. In order to preserve the anonymity of individual managers, the details of the particular company have been appropriately disguised.

2. A knowledge worker is defined as someone whose paid work involves significant time gathering, finding, analyzing, creating, producing or archiving information (Sellen et al., 2002).

3. Responses are numbered for in-text citation.

\section{References}

Abrams, L.C., Cross, R., Lesser, E. and Levin, D.Z. (2003), "Nurturing interpersonal trust in knowledge-sharing networks", Academy of Management Executive, Vol. 17 No. 4, pp. 64-77.

Akkinen, M. (2005), "Conceptual foundations of online communities", working paper (W-387), Information Systems Science, Helsinki School of Economics, Helsinki.

Anderson, P. (2007), "What is Web 2.0? Ideas, technologies and implications for education", JISC Technology \& Standards Watch, available at: www.jisc.ac.uk/media/documents/techwatch/tsw0701b. pdf (accessed 10 March 2009).

Ankolekar, A., Krötzsch, M., Tran, T. and Vrandecic, D. (2008), "The two cultures: mashing up Web 2.0 and the semantic web", Web Semantics: Science, Services and Agents on the World Wide Web, Vol. 6 No. 1 , pp. 70-5.

Ardichvili, A., Page, V. and Wentling, T. (2003), "Motivation and barriers to participation in virtual knowledge-sharing communities practice", Journal of Knowledge Management, Vol. 7 No. 1, pp. 64-77.

Ardichvili, A., Maurer, M., Li, W., Wentling, T. and Stuedemann, R. (2006), "Cultural influences on knowledge sharing through online communities of practice", Journal of Knowledge Management, Vol. 10 No. 1, pp. 94-107.

Barson, R., Foster, G., Struck, T., Ratchev, S., Pawar, K., Weber, F. and Wunram, M. (2000), "Inter- and intra-organizational barriers to sharing knowledge in the extended supply chain", e2000 Conference Proceedings, University of Nottingham, Nottingham.

Blau, P.M. (1964), Exchange and Power in Social Life, John Wiley \& Sons, New York, NY.

Bock, G.W., Zmud, R.W., Kim, Y.G. and Lee, J.N. (2005), "Behavioral intention formation in knowledge sharing: examining the roles of extrinsic motivators, social-psychological forces, and organizational climate", MIS Quarterly, Vol. 29 No. 1, pp. 87-111.

Boulos, M. and Wheeler, S. (2007), "The emerging Web 2.0 social software: an enabling suit of sociable technologies in health and health care education", Health Information and Libraries Journal, Vol. 24 No. 1, pp. 2-23.

Bughin, J. and Manyika, J. (2007), "How businesses are using Web 2.0: a McKinsey global survey", McKinsey Quarterly, March. 
Cabrera, A. and Cabrera, E.F. (2002), "Knowledge-sharing dilemmas", Organization Studies, Vol. 23 No. 5, pp. 687-710.

Cabrera, A., Collins, W.C. and Salgado, J.F. (2006), "Determinant of individual engagement in knowledge sharing", The International Journal of Human Resource Management, Vol. 17 No. 2, pp. 245-64.

Chennamaneni, A. (2006), "Determinants of knowledge sharing behaviors: developing and testing an integrated theoretical model", Doctoral Dissertation, the University of Texas at Arlington, Arlington, TX.

Davenport, H.T. and Prusak, L. (1998), Working Knowledge: How Organizations Manage What They Know, Harvard Business School Press, Boston, MA.

Dennison, R. (2006), "(2006) Using wikis for collaboration and KM at BT", Knowledge Management Review, Vol. 9 No. 5, p. 5, available at: www.melcrum.com/offer/kmr/_pdf/wikis at BT.pdf (accessed 10 March, 2009).

Drucker, P.F. (1999), "Knowledge worker productivity: the biggest challenge", California Management Review, Vol. 41 No. 2, pp. 79-94.

Hazlett, S.A., McAdam, R. and Gallagher, S. (2005), "Theory building in knowledge management: in search of paradigms", Journal of Management Inquiry, Vol. 14 No. 1, pp. 31-42.

Hsu, M.H., Ju, T.L., Yen, C.H. and Chang, C.M. (2007), "Knowledge sharing behavior in virtual communities: the relationship between trust, self-efficacy, and outcome expectations", International Journal of Human-Computer Studies, Vol. 65 No. 2, pp. 153-69.

Ipe, M. (2003), "Knowledge sharing in organizations: a conceptual framework", Human Resource Development Review, Vol. 2 No. 4, pp. 337-59.

Kainy, O. (2007), Enterprise Wiki: An Emerging Technology to be Considered by the AEC Industry, available at: www.aecbytes.com/viewpoint/2007/issue_31.html (accessed 10 March, 2009).

Kaiser, S., Muller-Seitz, G., Lopes, M.P. and Cunha, M. (2007), "Weblog-technology as a trigger to elicit passion for knowledge", Organization, Vol. 14 No. 3, pp. 391-412.

Kuhlen, R. (2003), "Change of paradigm in knowledge management - framework for the collaborative production and exchange of knowledge", paper presented at the 69th IFLA General Conference and Council, 30 August 2003, Berlin.

Levy, M. (2009), "WEB 2.0 implications on knowledge management", Journal of Knowledge Management, Vol. 13 No. 1, pp. 120-34.

McAfee, A. (2006a), "Enterprise 2.0: The dawn of emergent collaboration", MIT Sloan Management Review, Vol. 47 No. 3, pp. 21-8.

McAfee, A. (2006b), "Evangelizing in the empty quarter, the impact of IT on businesses and their leaders" (Blog), available at: blog.hbs.edu/faculty/amcafee/index.php/faculty_amcafee_v3/ evangelizing_in_the_empty_quarter/ (accessed 10 March 2009).

McAfee, A. (2006c), "The 9X e-mail problem, the impact of IT on businesses and their leaders"' (Blog), available at: blog.hbs.edu/faculty/amcafee/index.php/faculty_amcafee_v3/the_9x_email_problem/ (accessed 10 March 2009).

McDermott, R. (1999), "Why information technology inspired but cannot deliver knowledge management", California Management Review, Vol. 41 No. 4, pp. 103-17.

McDermott, R. and O'Dell, C. (2001), "Overcoming culture barriers to sharing knowledge", Journal of Knowledge Management, Vol. 5 No. 1, pp. 76-85.

Oliver, S. and Kandadi, K.R. (2006), "How to develop a knowledge culture in organizations? A multiple case study of large distributed organizations", Journal of Knowledge Management, Vol. 10 No. 4, pp. 6-24.

O'Reilly, T. (2005), "What is Web 2.0: design patterns and business models for the next generation of software", O’Reilly Media, available at: www.oreillynet.com/lpt/a/6228/ (accessed 10 March 2009).

Pachler, N. and Daly, C. (2009), "Narrative and learning with Web 2.0 technologies: towards a research agenda", Journal of Computer Assisted Learning, Vol. 25 No. 1, pp. 6-18. 
Riege, A. (2007), "Actions to overcome knowledge transfer barriers in MNCs", Journal of Knowledge Management, Vol. 11 No. 1, pp. 48-67.

Rogers, Y. (1994), "Exploring obstacles: integrating CSCW in evolving organizations", Proceedings of the Conference on Computer Supported Cooperative Work, October 22-26, 1994, Chapel Hill, NC, USA, ACM, New York, NY, pp. 67-77.

Rollett, H., Lux, M., Strohmaier, M., Gisela Dösinger, G. and Tochtermann, K. (2007), "The Web 2.0 way of learning with technologies", International Journal of Learning Technology, Vol. 3 No. 1, pp. 87-107.

Sellen, A.J., Murphy, R. and Shaw, K.L. (2002), "How knowledge workers use the web", Proceedings of the SIGCHI Conference on Human Factors in Computing Systems, April 2002, Vol. 2002, ACM, New York, NY, pp. 227-34.

Semple, E. (2007), "The 100\% guaranteed easiest way to enterprise 2.0?", available at: http:// theobvious.typepad.com/blog/2007/03/the_100_guarant.html (accessed 10 March 2009).

Strauss, A. and Corbin, J. (1990), Basics of Qualitative Research: Grounded Theory, Procedures, and Techniques, Sage, Newbury Park, CA.

Thaler, R. (1980), "Towards a positive theory of consumer choice", Journal of Economic Behavior and Organization, Vol. 1 No. 1, pp. 39-60.

Wasko, M. and Faraj, S. (2000), "It is what one does: why people participate and help others in electronic communities of practice", Journal of Strategic Information Systems, Vol. 9, pp. 155-73.

Wasko, M. and Faraj, S. (2005), "Why should I share? Examining social capital and knowledge contribution in electronic networks of practice", MIS Quarterly, Vol. 29 No. 1, pp. 35-57.

Weinberger, D. (2007), "The real difference between the two 2.0s", KM World, Vol. 16 No. 2, available at: www.kmworld.com/Articles/Column/David-Weinberger/The-real-difference-between-the-two-2.0s19130.aspx (accessed 10 March, 2009).

\section{About the authors}

Sotirios Paroutis is Assistant Professor of Strategic Management at Warwick Business School. He holds a PhD in Strategy and Organization from the School of Management, University of Bath. His current research focuses on the practices of strategy teams, the relationship between organizing and strategizing, and the capabilities required by managers to practice strategy in FTSE-100 multibusiness firms. His broader research interests include the study of strategizing processes and practices in complex organizations in the UK and globally. Sotirios Paroutis is the corresponding author and can be contacted at: Sotirios.Paroutis@wbs.ac.uk

Alya Al Saleh holds a MSc in Marketing and Strategy from Warwick Business School and a Bachelor's of Commerce from the University of Ottawa. Alya examined knowledge sharing using Web 2.0 technologies during an internship at a large multinational firm in the UK. She currently works as a Business Analyst at Shell E\&P International.

To purchase reprints of this article please e-mail: reprints@emeraldinsight.com Or visit our web site for further details: www.emeraldinsight.com/reprints 